\title{
Acupoint Catgut Embedding versus Acupuncture for Simple Obesity A Systematic Review and Meta- Analysis of Randomized Controlled Trials
}

\section{Jiali Wei}

Beijing University of Chinese Medicine https://orcid.org/0000-0003-2383-1416

\section{Lily Lai}

University of Southampton

\section{Zhechao Lin}

Beijing University of Chinese Medicine

Jianping Liu

Beijing University of Chinese Medicine

Mei Han ( $\square$ hanmeizoujin@163.com )

Beijing University of Chinese Medicine https://orcid.org/0000-0001-6883-3891

\section{Research}

Keywords: Acupoint Catgut Embedding; Acupuncture treatment; Simple obesity; Meta-Analysis

Posted Date: January 18th, 2021

DOI: https://doi.org/10.21203/rs.3.rs-145339/v1

License: (c) (i) This work is licensed under a Creative Commons Attribution 4.0 International License. Read Full License 


\section{Abstract}

Background: Acupuncture is very popular for reducing weight in China, in this work, we evaluate the clinical effectiveness and safety of acupoint catgut embedding and acupuncture on simple obesity by Metaanalysis.

Methods: Studies on clinical randomized controlled trials of acupoint catgut embedding for simple obesity which were published from January 2015 to November 2020 were searched in PubMed, VIP, CNKI and Wanfang databases. And those that met the inclusion criteria were screened. RevMan5.3 was used for Meta-analysis of effectiveness rate, BMI, waist circumference and body mass. The "Risk of Bias" tool was used to evaluate the quality of included studies. R studio software was used for the measurement of publication bias.

Results: A total of 33 studies were included for meta-analysis, including 2,685 patients with simple obesity. Meta-analysis results showed the comparison of effectiveness rate was $\mathrm{RR}=1.12,95 \% \mathrm{Cl}[1.08,1.16]$, the comparison of $\mathrm{BMI}$ was $\mathrm{MD}=-1.11,95 \% \mathrm{Cl}[-2.04,-0.18]$, the comparison of waist circumference was $\mathrm{MD}=-2.27,95 \% \mathrm{Cl}[-4.26,-0.28]$, and the comparison of body mass was $\mathrm{MD}=-2.24,95 \% \mathrm{Cl}[-3.78,-0.71]$. On the basis of diet and exercise intervention, the effectiveness rate $\mathrm{RR}=2.11,95 \% \mathrm{Cl}[1.38,3.24], \mathrm{BMI} \mathrm{MD}=-0.88$, $95 \% \mathrm{Cl}[-1.35,-0.40]$, waist circumference $\mathrm{MD}=-1.10,95 \% \mathrm{Cl}[-4.27,2.07]$ and body mass $\mathrm{MD}=-0.68,95 \% \mathrm{Cl}$ $[-2.90,1.54]$.The risk of bias of included literatures was low.

Conclusions: Acupoint catgut embedding therapy was slightly better than acupuncture therapy in effectiveness rate, BMI, waist circumference and body mass. Moreover, the treatment frequency of acupoint catgut embedding is less with larger stimulation intensity, which is more conducive to clinical promotion.

\section{Background}

Simple obesity is a common form of obesity,which is predominantly caused by a greater intake of calories than that expended by human body. Patients with simple obesity do not have underlying endocrine disorders or related diseases of metabolic illnesses and the fat distribution throughout the body is relatively even, rather than being concentrated in particular areas such as the abdomen. From 1985 to 2017, the global average Body Mass Index (BMI) increased by more than $55 \%{ }^{[1]}$, indicating an increasingly prevalent and serious issue worldwide. Nowadays, there are about 630 million obesity people worldwide. Obese population is close to 100 million in China, which is the world's largest, accounting for nearly $10 \%$ of the country's population ${ }^{[2]}$.This demonstrates that obesity becomes an important public health matter in China.

At present, the treatment of simple obesity consists mainly of diet and exercise therapy, biomedical treatments such as weight loss medications or surgical treatment and Traditional Chinese Medicine (TCM) therapy. Although diet and exercise therapy can be extremely effective, adherence to treatment is notoriously poor and typically requires a significant treatment course of more than 4 months. Biomedical 
approaches such as weight loss medications and surgical intervention can bring about rapid weight loss but can unfortunately be associated with serious side-effects affecting gastrointestinal function or even nervous system issues ${ }^{[3]}$.

TCM for simple obesity include acupuncture and specialized acupuncture techniques such as electroacupuncture(EA) and acupoint catgut embedding (ACE). Acupuncture can support weight management through its effects on the endocrine, gastrointestinal and nervous systems. For example, studies have shown that ACE can increase insulin sensitivity to make patients feel full to reduce food intake $^{[4]}$. Acupuncture can also have a good effect. This is further supported by evidence from clinical research. The results of recent randomized controlled trials (RCTs) have demonstrated that patients with simple obesity treated with electroacupuncture combined with diet and exercise experienced $4.84 \pm 7.38 \mathrm{~kg}$ greater weight loss when compared with patients undergoing diet and exercise alone ${ }^{[5]}$.Another specialized acupuncture technique, ACE, has also shown promising results for abdominal obesity. A recent metaanalysis showed that the average weight loss of patients in the group treated with ACE was $1.35 \mathrm{~kg}$ greater than that in the electroacupuncture group ${ }^{[6]}$. When considering the external validity of these results,however, electroacupuncture typically requires multiple treatment sessions a week which can affect the overall acceptability of the intervention. In contrast, ACE treatment is carried out once every 7 to 10 days and which could result in considerably greater patient adherence and therefore greater overall effectiveness. We aimed to review the clinical evidence comparing ACE against acupuncture for simple obesity and conducted a systematic review and meta-analysis of the available evidence to date.

\section{Methods}

\subsection{Inclusion Criteria}

We included RCTs involving patients diagnosed with simple obesity. Studies were eligible if the treatment group received ACE and the control group received wither manual acupuncture (MA) or electroacupuncture (EA). Diet and exercise interventions were permitted if they were administered to both groups. RCTs were eligible if they evaluated relevant outcomes such as effectiveness rate,BMI, waist circumference and body mass.

\subsection{Study Review and Screening}

We conducted a search of literature published between January 2015 and November 2020 across four databases - China National Knowledge Infrastructure (CNKI), Weipu Chinese Science and Technology Journal (VIP), China Wanfang Database (Wanfang) and PubMed. Search terms such as'simple obesity'and'acupoint catgut embedding'were used. We excluded duplicate publications, studies that evaluated other obese populations and studies that did not involve ACE as the treatment intervention. Preliminary screening was carried out using NoteExpress by reading the titles and abstracts. Full texts of the remaining literature were then retrieved for final screening. Screening was carried out by Zhechao Lin and Mei Han with disagreements resolved by a third author Lily Lai if necessary.

\subsection{Data Extraction}


We established a data collection form and data was extracted independently by two reviewers Jiali Wei and Mei Han. We extracted information such as the general characteristics of the studies, characteristics of the participants, details of interventions, outcome measures used and research findings.

\subsection{Quality Assessment}

We evaluated the methodological quality using the Risk of Bias tool and according to the standards recommended by the Cochrane Handbook for Systematic Reviews of Interventions. We completed an assessment evaluating risk of bias according to the following categories: random sequence generation, allocation concealment, blinding of participants and personnel, blinding of outcome assessment, incomplete outcome data, selective reporting and any other bias. Due to the particularity of the interventions, we deemed it almost impossible to blind practitioners and participants. Therefore, if the data statistician was blinded, we assessed the study as being at low risk of bias. Studies reporting on reasons for withdrawals or dropouts and with comparable dropout rates between groups were also assessed as being at low risk.

$\mathrm{BMI}$ and waist circumference are the most objective indicators for evaluating simple obesity ${ }^{[7]}$. Therefore, if these two outcomes were not reported, the study was evaluated as being at high risk of bias. The risk of bias was also evaluated independently by two reviewers Jianping Liu and Zhechao Lin and assessments were compared. Any disagreements were resolved through discussion with a third reviewer Lily Lai.

\subsection{Statistics Analysis}

We used Review Manager 5.3 to conduct the quantitative synthesis of the review data. Relative risk (RR) was used for dichotomous data. The remaining outcome indicators were continuous and the mean difference (MD) was calculated for these measures.

Heterogeneity between RCTs was evaluated using $X^{2}$ and $I^{2}$. When $I^{2} \leq 50 \%$, we used a fixed effects model for analysis. High heterogeneity was determined when $\mathrm{I}^{2} \geq 75 \%$, and in this case, it would be temporarily abandoned. A 95\% confidence interval $(\mathrm{Cl})$ was calculated for each analysis and $p<0.05$ considered statistically significant.

\subsection{Measurement of Publication Bias}

Metabais function in meta package of $\mathrm{R}$ studio software for the measurement of publication bias.

\subsection{Informed consent and Ethical review}

This study is a review of literature, not a clinical trial. So informed consent or ethical review is not required in our study.

\section{Results}

\subsection{Studies Searching and Screening Procedure}


A total of 460 studies were obtained of which 87 were duplicates and which were excluded. After screening, 40 full text studies were obtained. After full-text screening, 33 were eligible for inclusion and 7 studies were excluded. 33 RCTs were eventually included in this meta-analysis. The screening process is illustrated in Fig. 1.

\subsection{Characteristics of Included studies}

All 33 studies included ACE in the treatment group. ACE was compared against MA in 19 studies and against EA in 14 studies.Adjunctive treatment of diet and exercise was adopted in 8 RCTs $[11,14,15,25,28,29$, 35, 39]. The 33 included studies enrolled a total of 2,685 participants, including 1,349 in the ACE group and 1,336 in the MA/EA group. The frequency of treatment and characteristics of the participants in each included RCT were very similar, with patients of similar age. The treatment duration was between 4-12 weeks. Among the included studies, the most frequently used acupoints were Zhongwan (प[CV12), Tianshu

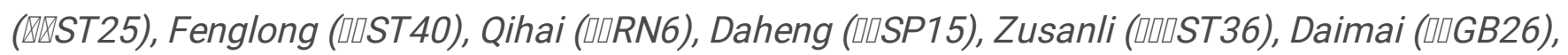

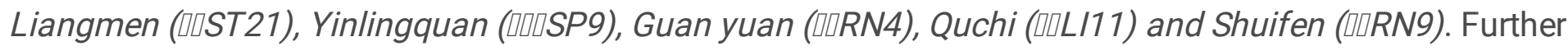
information regarding the characteristics of the studies can be found in Table 1. 
Table 1

Characteristics of included studies.

\begin{tabular}{|c|c|c|c|c|c|c|c|c|c|}
\hline \multirow[t]{2}{*}{ ID } & \multirow[t]{2}{*}{$\begin{array}{l}\text { Sample } \\
\text { Size(T/C) }\end{array}$} & \multirow[t]{2}{*}{ Age } & \multicolumn{2}{|c|}{ Interventions } & \multicolumn{2}{|c|}{$\begin{array}{l}\text { Treatment } \\
\text { Frequency }\end{array}$} & \multicolumn{2}{|c|}{$\begin{array}{l}\text { Treatment } \\
\text { Duration }\end{array}$} & \multirow{2}{*}{$\begin{array}{l}\text { Diet } \\
\text { and } \\
\text { Exercise }\end{array}$} \\
\hline & & & $\mathrm{T}$ & C & $T$ & C & $\mathrm{T}$ & $\mathrm{C}$ & \\
\hline $\begin{array}{l}\text { Chen } \\
\text { RZ2016 }\end{array}$ & $47 / 47$ & $\begin{array}{l}42.8 \\
\pm 2.9\end{array}$ & ACE & MA & $1 / 1 w k$ & $6 / 1 w k$ & $8 w k s$ & $8 w k s$ & NO \\
\hline $\begin{array}{l}\text { Chen } \\
\text { YY2015 }\end{array}$ & $40 / 40$ & 29 & ACE & MA & $1 / 3 w k s$ & $4 / 1 w k$ & $12 w k s$ & $10 w k s$ & NO \\
\hline $\begin{array}{l}\text { Di } \\
\text { YL2016 }{ }^{[10]}\end{array}$ & $41 / 41$ & $\begin{array}{l}31.5 \\
\pm 6.8\end{array}$ & ACE & MA & $1 / 1 w k$ & $4 / 1 w k$ & $8 w k s$ & $8 w k s$ & NO \\
\hline $\begin{array}{l}\text { Duan } \\
\text { YQ2018 }\end{array}$ & $25 / 25$ & $\begin{array}{l}18- \\
45\end{array}$ & ACE & MA & $1 / 15 \mathrm{ds}$ & $7 / 1 w k$ & $8 w k s$ & $8 w k s$ & YES \\
\hline $\begin{array}{l}\mathrm{He} \\
\mathrm{LY} 2017^{[12]}\end{array}$ & $30 / 28$ & $\begin{array}{l}38.2 \\
\pm 2.8\end{array}$ & ACE & EA & $1 / 2 w k s$ & $5 / 1 w k$ & $12 w k s$ & $12 w k s$ & NO \\
\hline $\begin{array}{l}\text { Huang } \\
\text { Q2020[13] }\end{array}$ & $39 / 39$ & $\begin{array}{l}38.27 \\
\pm 2.52\end{array}$ & ACE & MA & $1 / 1 w k$ & $4 / 1 w k$ & $12 w k s$ & $12 w k s$ & NO \\
\hline $\begin{array}{l}\text { Huang } \\
\text { W2017 }\end{array}$ & $40 / 40$ & $\begin{array}{l}20- \\
45\end{array}$ & ACE & EA & $1 / 10 \mathrm{ds}$ & $4 / 1 w k$ & $8 w k s$ & $8 w k s$ & YES \\
\hline $\begin{array}{l}\text { Jin } \\
\text { WW2016 }\end{array}$ & $80 / 80$ & $\begin{array}{l}39.23 \\
\pm 4.80\end{array}$ & ACE & EA & $1 / 2 w k s$ & $5 / 1 w k$ & $6 w k s$ & $6 w k s$ & YES \\
\hline $\begin{array}{l}\mathrm{Li} \\
\mathrm{MM} 2017^{[16]}\end{array}$ & $30 / 30$ & 37.43 & ACE & EA & $1 / 2 w k s$ & $2 / 1 w k$ & $8 w k s$ & $8 w k s$ & NO \\
\hline $\begin{array}{l}\text { Li } \\
\text { MM2018[17] }\end{array}$ & $33 / 33$ & 31.61 & ACE & EA & $1 / 2 w k s$ & $2 / 1 w k$ & $8 w k s$ & $8 w k s$ & NO \\
\hline $\begin{array}{l}\mathrm{Li} \\
\text { QL2016[18] }\end{array}$ & $40 / 40$ & $\begin{array}{l}33.45 \\
\pm 2.35\end{array}$ & ACE & EA & $1 / 15 \mathrm{ds}$ & $2 / 1 w k$ & $12 w k s$ & $12 w k s$ & NO \\
\hline $\begin{array}{l}\text { Liu } \\
\text { Y2019[19] }\end{array}$ & $31 / 31$ & $\begin{array}{l}37.29 \\
\pm \\
11.83\end{array}$ & ACE & EA & $1 / 2 w k s$ & $3 / 1 w k$ & $8 w k s$ & $8 w k s$ & NO \\
\hline Qi L2016[20] & $30 / 30$ & $\begin{array}{l}18- \\
60\end{array}$ & ACE & MA & $1 / 1 w k$ & $7 / 1 w k$ & $8 w k s$ & $8 w k s$ & NO \\
\hline $\begin{array}{l}\text { Ren } \\
\text { CC2016 [21] }\end{array}$ & $36 / 36$ & $32 \pm 9$ & ACE & EA & $1 / 1 w k$ & $4 / 1 w k$ & 8wks & $8 w k s$ & NO \\
\hline
\end{tabular}

Notes: T(Treatment Group),C(Control Group), MA(Manual Acupuncture), EA(Electroacupuncture), ACE(Acupoint Catgut Embedding) 


\begin{tabular}{|c|c|c|c|c|c|c|c|c|c|}
\hline \multirow[t]{2}{*}{ ID } & \multirow[t]{2}{*}{$\begin{array}{l}\text { Sample } \\
\text { Size(T/C) }\end{array}$} & \multirow[t]{2}{*}{ Age } & \multicolumn{2}{|c|}{ Interventions } & \multicolumn{2}{|c|}{$\begin{array}{l}\text { Treatment } \\
\text { Frequency }\end{array}$} & \multicolumn{2}{|c|}{$\begin{array}{l}\text { Treatment } \\
\text { Duration }\end{array}$} & \multirow{2}{*}{$\begin{array}{l}\text { Diet } \\
\text { and } \\
\text { Exercise }\end{array}$} \\
\hline & & & $\mathbf{T}$ & C & $\mathbf{T}$ & $\mathrm{C}$ & $\mathrm{T}$ & $\mathrm{C}$ & \\
\hline $\begin{array}{l}\text { Sun } \\
\text { FJ2020[22] }\end{array}$ & $25 / 25$ & $\begin{array}{l}26.15 \\
\pm 5.9\end{array}$ & ACE & MA & $1 / 21 \mathrm{ds}$ & $4 / 1 w k$ & $8 w k s$ & $8 w k s$ & NO \\
\hline $\begin{array}{l}\text { Wang } \\
\text { Z2020 }\end{array}$ & $56 / 56$ & $\begin{array}{l}43.5 \\
\pm 2.7\end{array}$ & ACE & MA & $1 / 4 \mathrm{wks}$ & $2 / 1 w k$ & $4 w k s$ & $4 w k s$ & NO \\
\hline $\begin{array}{l}\text { Wu } \\
\text { XM2015 }{ }^{[24]}\end{array}$ & $32 / 30$ & $\begin{array}{l}33 \pm \\
11\end{array}$ & ACE & EA & $1 / 10 d s$ & $1 / 1 w k$ & $6 w k s$ & $6 w k s$ & NO \\
\hline $\begin{array}{l}\text { Wu } \\
\text { XN2015[25] }\end{array}$ & $80 / 80$ & $\begin{array}{l}41.06 \\
\pm \\
12.05\end{array}$ & ACE & EA & $1 / 1 w k$ & $1 / 1 w k$ & $12 w k s$ & $12 w k s$ & YES \\
\hline $\begin{array}{l}\text { Wu } \\
\text { XN2017 }\end{array}$ & $76 / 73$ & $\begin{array}{l}43.17 \\
\pm 11.0\end{array}$ & ACE & EA & $1 / 1 w k$ & $4 / 1 w k$ & $12 w k s$ & $12 w k s$ & NO \\
\hline $\begin{array}{l}\text { Xu } \\
\text { DJ2019[27] }\end{array}$ & $30 / 30$ & $\begin{array}{l}29.6 \\
\pm 4.4\end{array}$ & ACE & MA & $1 / 15 d s$ & $7 / 1 w k$ & $12 w k s$ & $12 w k s$ & NO \\
\hline $\begin{array}{l}\text { Xu } \\
\text { WZ2017 } \\
\text { [28] }\end{array}$ & $30 / 30$ & $\begin{array}{l}30.42 \\
\pm 6.58\end{array}$ & ACE & MA & $1 / 1 w k$ & $3 / 1 w k$ & $8 w k s$ & $8 w k s$ & YES \\
\hline $\begin{array}{l}\text { Yan } \\
\text { XR2015[29] }\end{array}$ & $27 / 27$ & $\begin{array}{l}32.35 \\
\pm \\
11.93\end{array}$ & ACE & EA & $1 / 10 d s$ & $4 / 1 w k$ & $4 w k s$ & $6 w k s$ & YES \\
\hline $\begin{array}{l}\text { Yang } \\
\text { Q2015[30] }\end{array}$ & $39 / 33$ & 41.4 & ACE & MA & $1 / 1 w k$ & $4 / 1 w k$ & $10 w k s$ & 10wks & NO \\
\hline $\begin{array}{l}\text { Yang } \\
\text { YF2015[31] }\end{array}$ & $65 / 65$ & $\begin{array}{l}35.5 \\
\pm 6.3\end{array}$ & ACE & MA & $1 / 1 w k$ & $5 / 1 w k$ & $8 w k s$ & $8 w k s$ & NO \\
\hline $\begin{array}{l}\text { Zhang } \\
\text { H2017 }\end{array}$ & $40 / 40$ & $\begin{array}{l}18- \\
55\end{array}$ & ACE & MA & $1 / 1 w k$ & $4 / 1 w k$ & $12 w k s$ & $12 w k s$ & NO \\
\hline $\begin{array}{l}\text { Zhang } \\
\text { HT2015 }\end{array}$ & $30 / 30$ & $\begin{array}{l}18- \\
60\end{array}$ & ACE & MA & $1 / 2$ wks & $4 / 1 w k$ & $6 w k s$ & $6 w k s$ & NO \\
\hline $\begin{array}{l}\text { Zhang } \\
\text { Y2017 }\end{array}$ & $33 / 33$ & $\begin{array}{l}42.75 \\
\pm \\
12.21\end{array}$ & ACE & MA & $1 / 15 d s$ & $7 / 1 w k$ & $12 w k s$ & $12 w k s$ & NO \\
\hline $\begin{array}{l}\text { Zhao } \\
\text { HY2015 }\end{array}$ & $50 / 50$ & 42.21 & ACE & EA & $1 / 10 d s$ & $5 / 1 w k$ & $6 w k s$ & $6 w k s$ & YES \\
\hline $\begin{array}{l}\text { Zheng } \\
\text { X2015 }\end{array}$ & $40 / 40$ & $\begin{array}{l}15- \\
56\end{array}$ & ACE & MA & $1 / 2$ wks & $4 / 1 w k$ & $12 w k s$ & $12 w k s$ & NO \\
\hline
\end{tabular}




\begin{tabular}{|c|c|c|c|c|c|c|c|c|c|}
\hline \multirow[t]{2}{*}{ ID } & \multirow[t]{2}{*}{$\begin{array}{l}\text { Sample } \\
\text { Size(T/C) }\end{array}$} & \multirow[t]{2}{*}{ Age } & \multicolumn{2}{|c|}{ Interventions } & \multicolumn{2}{|c|}{$\begin{array}{l}\text { Treatment } \\
\text { Frequency }\end{array}$} & \multicolumn{2}{|c|}{$\begin{array}{l}\text { Treatment } \\
\text { Duration }\end{array}$} & \multirow{2}{*}{$\begin{array}{l}\text { Diet } \\
\text { and } \\
\text { Exercise }\end{array}$} \\
\hline & & & $\mathbf{T}$ & $\mathrm{C}$ & $T$ & C & $T$ & C & \\
\hline $\begin{array}{l}\text { Zheng } \\
\text { X2018 }\end{array}$ & $43 / 43$ & $41 \pm 5$ & ACE & EA & $1 / 1 w k$ & $4 / 1 w k$ & $8 w k s$ & $8 w k s$ & NO \\
\hline $\begin{array}{l}\text { Zhou } \\
\text { LJ2017 }\end{array}$ & $33 / 33$ & $\begin{array}{l}18- \\
60\end{array}$ & ACE & MA & $1 / 4 \mathrm{wks}$ & $2 / 1 w k$ & $4 \mathrm{wks}$ & $4 \mathrm{wks}$ & NO \\
\hline $\begin{array}{l}\text { Zhou } \\
\text { W2019[39] }\end{array}$ & $45 / 45$ & $\begin{array}{l}21- \\
45\end{array}$ & ACE & MA & $1 / 10 \mathrm{ds}$ & $4 / 1 w k$ & $8 w k s$ & $8 w k s$ & YES \\
\hline $\begin{array}{l}\text { Zhu } \\
\text { Q2017[40] }\end{array}$ & $33 / 33$ & $\begin{array}{l}18- \\
60\end{array}$ & ACE & MA & $1 / 2 w k s$ & $4 / 1 w k$ & $8 w k s$ & $8 w k s$ & NO \\
\hline
\end{tabular}

\subsection{Quality Assessment}

Figure 2 provides a summary of the risk of bias evaluation of eligible studies across the 7 specific areas of bias mentioned earlier. 12 studies $[10,17,19,21,22,25,26,27,28,29,30,34]$ were randomly assigned by random number table method and 2 studies ${ }^{[14,39]}$ used opaque envelopes. Blinding was not adopted in any of the

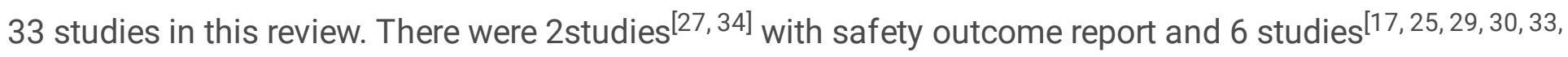
${ }^{35]}$ reported on withdrawals. There was no conflict of interest.

\subsection{Results of Meta-Analysis 3.4.1 Effectiveness Rate}

The nationally recognized method of obesity assessment ${ }^{[34]}$ was adopted to define the effectiveness rate. Significant effect: Body Mass decreases at least 5 kilograms or Waist Circumference decreases at least 5 centimeters. Effective: Body Mass decreases at least 3 kilograms or Waist Circumference decreases at least 3 centimeters. The ratio of the number of significant and effective patients with the total number of patients in this group is the effectiveness rate. Most of the studies included in this study adopted this definition of effectiveness rate.

In the comparison of ACE versus acupuncture, 25 studies reported effectiveness rate. Quantitative synthesis of the results showed that ACE performed slightly better than acupuncture in terms of the effectiveness rate (RR $=1.12,95 \% \mathrm{Cl}[1.08,1.16])$ (Fig. 3(a)).

8 studies reported the effectiveness rate for the comparison of ACE plus diet and exercise versus acupuncture plus diet and exercise. Meta-analysis showed a better effect in ACE plus diet and exercise when compared with acupuncture plus diet and exercise (RR $=2.11,95 \% \mathrm{Cl}[1.38,3.24])$ (Fig. 4(a)).

\subsubsection{BMI}


When looking at studies reporting on BMI as an outcome, 18 studies compared ACE against acupuncture. Meta-analysis showed that BMI was statistically significantly reduced in the ACE group compared with acupuncture (MD=-1.11, 95\% Cl [-2.04, -0.18]) (Fig. 3(b)).

6 studies comparing ACE plus diet and exercise against acupuncture plus diet and exercise reported on $\mathrm{BMI}$ as an outcome measure. Quantitative synthesis showed no significant difference between the two groups (MD=-0.88, 95\% Cl [-1.35,-0.40]) (Fig. 4(b)).

\subsubsection{Waist Circumference}

A total of 13 studies comparing ACE against acupuncture used waist circumference as an outcome measure. Meta-analysis showed that WC was statistically significantly reduced in the ACE group compared with acupuncture(MD=-2.27, 95\% Cl [-4.26,-0.28]) (Fig. 3(c)).

When comparing ACE plus diet and exercise against acupuncture plus diet and exercise, 5 studies reported waist circumference as an outcome. The combined analysis showed that ACE plus diet and exercise had a slight advantage over acupuncture plus diet and exercise (MD=-1.10, 95\% $\mathrm{Cl}[-4.27,2.07])$ for this outcome (Fig. 4(c)).

\subsubsection{Body Mass}

15 studies reporting on body mass compared ACE against acupuncture. Our quantitative synthesis found a statistically significant difference favoring ACE for body mass (MD=-2.24,95\% CI [-3.78,-0.71]) (Fig. 3(d)).

When comparing ACE plus diet and exercise against acupuncture plus diet and exercise (Fig. 4(d)), we pooled data from 4 studies using body mass as an outcome. Our analysis showed ACE plus diet and exercise had a little advantage compared with Acupuncture plus diet and exercise for the outcome of body mass (MD=-0.68, 95\% Cl [-2.90,1.54]) (Fig. 4(d)) .

\subsection{Measurement of Publication Bias}

According to the results of Egger test, $t=0.17933, p$-value $=0.8599>0.05$, suggesting that the included studies were likely to be free from publication bias.

\subsection{Adverse Events}

2 studies ${ }^{[27,34]}$ reported on safety. Some participants reported pain at the ACE site lasting for one week. Some participants reported mild pain at the embedding site which subsided after 2-3 days. Some participants experienced ecchymosis under the skin of the embedding site, which dissipated after symptomatic treatment. There were 6 studies $[17,25,29,30,33,35]$ reported on withdrawals as a result of treatment-related pain and a lack of knowledge about simple obesity.

\section{Discussions}

\subsection{Principal Findings}


This meta-analysis of RCTs showed that ACE was statistically significantly better than acupuncture in terms of effectiveness rate, BMI, waist circumference and body mass.

\subsection{Limitations of the study}

Due to the particularity of intervention measures, it is impossible to blind the practitioners and participants. However, results evaluators and statisticians were rarely blinded in the included studies, which we believe may be the source of measurement bias. Some of the included studies also failed to provide clear details regarding participants who withdrew or who were lost-to-follow-up. As studies in this review were published in Chinese and conducted in China which may make the results of this review less generalizable to nonChinese populations.

\subsection{Implications for Clinical Practice}

The results of our review demonstrate that ACE has a statistically significant benefit when compared with acupuncture for simple obesity,for the outcomes of effectiveness rate, BMI, waist circumference and body mass. As an extension of acupuncture therapy, acupoint catgut is placed in ACE to achieve lasting stimulation of the acupoints.ACE can speed up the flow of qi and blood and enhance the metabolism of the body to achieve the purpose of treating obesity. ${ }^{[19]}$ Modern medicine believes that the mechanism of ACE may be increasing the expression of peroxisome proliferators-activated receptory PPAR- $y$ mRNA in adipose tissue and inhibiting the expression of visfatin in visceral adipose tissue so as to achieve multiple biological functions such as producing insulin, regulating immune and inflammatory responses, and promoting adipogenic differentiation and synthesis.It also can reduce uric acid levels in the blood of the obese patients and increase insulin sensitivity making the patients feel full to reduce food intake ${ }^{[40]}$.

Since ACE treatment is administered on a less frequent basis compared with acupuncture, patients are likely to find ACE treatment more acceptable and easier to comply with. ACE treatment also requires a shorter course of treatment, meaning that patients are likely to observe clinical benefits sooner than with diet and exercise and which in turn is likely to increase patient adherence and thus overall effectiveness. This review also found few adverse events associated with ACE treatment which provides additional advantage over biomedical options such as medications and surgical intervention which can be associated with serious adverse outcomes. In summary, our findings appear to suggest that ACE is clinically effective for important parameters in obesity and could be considered as first-line therapy for the management of simple obesity in adults.

\subsection{Implications for Future Research}

The results of our review highlight the poor methodological quality of the included studies. Future RCTs involving participants with simple obesity should consider reducing bias in particular by incorporating appropriate blinding methods to reduce performance bias, and by providing further details regarding participants' lost-to-follow-up.

\section{Conclusions}


In our meta-analysis, ACE appeared to provide statistically significant benefits compared with acupuncture for the outcomes of effectiveness rate, BMI, waist circumference and body mass. However, these findings need to be interpreted with caution owing to the poor methodological quality of the studies. More methodologically rigorous RCTs are required so that the effects of ACE for simple obesity can be understood more clearly.

\section{Abbreviations}

Body Mass Index (BMI)

Traditional Chinese Medicine (TCM)

Electroacupuncture(EA)

Acupoint catgut embedding (ACE)

Randomized controlled trials (RCTs)

Manual acupuncture (MA)

China National Knowledge Infrastructure (CNKI)

Weipu Chinese Science and Technology Journal (VIP)

China Wanfang Database (Wanfang)

Relative risk (RR)

Mean difference (MD)

Confidence interval (Cl)

Treatment Group(T)

Control Group(C)

Waist Circumference(WC)

\section{Declarations}

2.Ethics approval and consent to participate

This study is a review of literature, not a clinical trial. So informed consent or ethical review is not required in our study.

3.Consent to publish 
The paper is consent for publication.

4.Availability of data and materials

All data generated or analysed during this study are included in this published article.

5.Competing interests

There is no competing Interest.

6.Funding

The project of the National Natural Science Foundation of China (No. 81830115).

\section{Authors' Contributions}

The screening of titles and abstracts was carried out by Zhechao Lin and Mei Han with disagreements resolved by a third author Lily Lai if necessary.A data collection form was created and data was extracted independently by two reviewers Jiali Wei and Mei Han. The risk of bias was also evaluated independently by two reviewers Jianping Liu and Zhechao Lin and assessments were compared. Any disagreements were resolved through discussion with a third reviewer Lily Lai.All authors read and approved the final manuscript.

\section{Acknowledgements}

We don't have anyone to acknowledge.

\section{References}

1. Ramón Suárez-Medina. Ncd-Risc NR. F C. Rising rural body-mass index is the main driver of the global obesity epidemic in adults s41586-019-1171-x[J]. Nature, 2019, 569:260-4.

2. Committee of Obesity and Diabetes Surgeons. Surgeons' Branch, Chinese Medical Doctors association. An initiative to establish "China Obesity Day" on May 11. [J]. Chinese Journal of Obesity Metabolic Diseases. 2018;4(2):119.

3. Cui Jia-yu. Xie Xiao-hui. Progress of drug therapy for obesity [J]. Chinese Journal of New Drugs,2016,25(02):163-169. [Chinese].

4. Chen Li-shu. Wang Da-wei, Zhao Yong-hua. Discussion on the mechanism of acupoint catgut embedding in the treatment for obesity [J]. Chinese Acupuncture. 2008;38(03):319-23..[Chinese].

5. Comparative effectiveness. of electroacupuncture plus lifestyle modification treatment for patients with simple obesity and overweight: study protocol for a randomized controlled trial[J]. Trials. 2015;16(1):1-8.

6. Sheng Ji-li,Jin Xiao-qing,Zhu Jian-fang,Chen Yi-dan,Liu Xu. The Effectiveness of Acupoint Catgut Embedding Therapy for Abdominal Obesity: A Systematic Review and Meta-Analysis. [J]. Evidence- 
based Complementary and Alternative Medicine: eCAM,2019,2019.

7. Chinese guidelines on prevention and control of. overweight and obesity in adults (excerpt) [J]. Chinese journal of nutrition,2004,26(1):1-4.

8. Chen Rong-zhong. Acupuncture point bury line therapy in the treatment of simple obesity clinical research [J]. Journal of clinical medicine literature electron. 2016;3(43):8506-7. The DOI: 10.3877 / j.i SSN. 2095-8242.2016.43.012. [Chinese].

9. Chen Yuan-yuan. Li Nai-fang, Cui An-cheng, Chen Xiao-fang. Clinical observation of acupuncture combined with acupoint catgut embedding in the treatment of simple obesity [J]. Guangming Chinese Medicine,2015,30(06):1266-1268. [Chinese].

10. Di Yan-li. Discussion on the feasibility of applying acupoint catgut embedding for weight loss in simple obesity with damp obstruction disease with syndrome of damp retention due to spleen deficiency [J]. Chinese Medicine Clinical Study,2016,8(28):50-51. DOI:10.3969/j.issn.16747860.2016.28.023. [Chinese].

11. Duan Yun-qing, Jin C, Li C, et al. Acupuncture point bury line treatment of 25 cases of simple obesity clinical observation [J]. Yunnan Journal of Traditional Chinese Medicine. 2018;33(2):6:66-7. The DOI: 10.3969 / j.i SSN. 1007-2349.2018.02.032. [Chinese].

12. He Li-ya. Lu Wen-ming, Yang Jian-yong, Sun Wen-bo. Clinical observation of acupoint embedding therapy for 30 cases of obesity [J]. Chinese National Folk Medicine,2017,26(15):102-104. [Chinese].

13. Huang Q. Effect of acupoint embedding on weight and lipid status of simple obesity patients [J]. Chinese Journal of Foreign Medicine,2020,29(1):52-53.[Chinese].

14. Huang Wei W, Xia JC. Wang Li-hua, Yan Xiao-rong, Zhou Zhong-yu. Effect of acupoint catgut embedding therapy on insulin resistance in patients with simple obesity [J]. Chinese Journal of Traditional Chinese Medicine,2017,32(08):3646-3649. [Chinese].

15. Jin Wei-wei. Chen Zai-li. Therapeutic Effect of acupoint embedding combined with health education on simple obesity [J]. New Chinese Medicine. 2016;048(010):219-20. [Chinese].

16. Li Miao-miao, Jin-xia NI, Jie W, Xue F. Su Bu-yi, Wu Xiao-na. Clinical observation on the treatment of simple obesity with dampness resistance due to spleen deficiency by acupoint embedding therapy based on respiratory supplementation and diarrhea [J]. Journal of Guangzhou University of Traditional Chinese Medicine,2017,34(04):534-538. [Chinese].

17. Li Miao-Miao. Clinical study on acupoint embedding therapy and electroacupuncture therapy in the treatment of simple obesity with dampness resistance due to spleen deficiency [D]. Beijing University of Traditional Chinese Medicine,2018. [Chinese].

18. Li Qing-ling. Clinical effect analysis of acupoint catgut embedding therapy for simple obesity [J]. Frontiers in Medicine. 2016;6(024):29-30. [Chinese].

19. Liu Ying. Clinical observation of electroacupuncture therapy and acupoint embedding therapy in the treatment of simple obesity with damp obstruction disease with syndrome of damp retention due to spleen deficiency [D]. Nanjing University of Traditional Chinese Medicine,2019. [Chinese]. 
20. Qiao lei. Clinical effect observation of acupoint embedding intervention in simple obesity [J]. World's latest Medical Information Digest,2016,16(86):112 + 115. [Chinese].

21. Lizzy G. Bao-he. Comparative study on the maintenance time of acupoint embedding and electroacupuncture in the treatment of simple obesity [J]. Shanghai journal of Acupuncture,2016,35(11):1299-1302. DOI:10.13460/j.issn.1005-0957.2016.11.1299[Chinese].

22. Sun Feng-ju. To explore the effect of TCM syndrome differentiation combined with acupoint embedding in the treatment for simple obesity [J]. Electronic Journal of Clinical Medicine Literature,2020,7(54):38,40.[Chinese].

23. Wang, Zheng. Pang Xiu-hua, Asvagine. Effect of painless acupoint catgut embedding therapy in the treatment for simple obesity [J]. Journal of Contemporary Medicine,2020,18(7):196-197.[Chinese].

24. Wu Xiao-mei. Zheng Yi-shu, Zhou Hui-na. Influence of acupoint embedding and electroacupuncture on the treatment of simple obesity [J]. Contemporary Nurses (Mid-month),2015,(4):77-78.[Chinese].

25. Wu Xiang-nong. Summary of Professor Wang Guang-ding's academic thoughts and clinical experience-Back-shu points and front-mu points combination in acupoint embedding therapy for simple obesity [D]. Yunnan University of Traditional Chinese Medicine,2015.[Chinese].

26. Wu Xiang-nong. Liu Mei-fang, Xiong You-long. Yu jiao,Clinical study of acupoint embedding in the treatment for simple obesity [J]. Guangming Chinese Medicine,2017,32(03):400-403.[Chinese].

27. Xue Ding-jiang. Clinical observation of acupoint embedding in the treatment for simple obesity with damp obstruction disease with syndrome of damp retention due to spleen deficiency [D]. 2019. [Chinese].

28. Xu Wei-zhen. Clinical study on the treatment of postpartum obesity by three-needle acupoint embedding [D]. Guangzhou University of Traditional Chinese Medicine,2017.[Chinese].

29. Yan Xiao-rong. Comparative study on acupoint embedding and electroacupuncture in the treatment for simple obesity [D]. Hubei: Hubei University of Traditional Chinese Medicine,2015. DOI:10.7666/ D.d689085.[Chinese].

30. Yang Qian. Chen He-jun, Chen Fu-bin. Clinical observation of acupoint embedding in the treatment for obesity with damp obstruction disease with syndrome of damp retention due to spleen deficiency [J]. Xinjiang Chinese Medicine,2015,33(06):32-34.[Chinese].

31. Yang Yu-feng. Clinical efficacy of acupoint embedding therapy in the treatment of simple obesity [J]. Medical Aesthetics and Cosmetology (mid-month),201524(6):141-142.[Chinese].

32. Zhang $\mathrm{H}$, Ding $\mathrm{TH}$. Therapeutic effect of acupoint embedding therapy on simple obesity and its influence on blood lipids [J]. Journal of Modern Integrative Medicine,2017,26(12):1334-1336. DOI:10.3969/j.issn.1008-8849.2017.12.028.[Chinese].

33. Zhang Hong-tao. Clinical observation of acupoint catgut embedding in the treatment for simple obesity [C].[Chinese].

34. Zhang Y. Clinical efficacy of acupoint embedding in the treatment for simple obesity with damp obstruction disease with syndrome of damp retention due to spleen deficiency [D].[Chinese]. 
35. Zhao Hua-yi. Ai Bing-wei. Clinical Observation of acupoint embedding therapy for simple obesity [J]. Chinese Medicine Clinical Research,2015(4):41-43. DOI:10.3969/ J.issn.1674-7860.2015.4.015. [Chinese].

36. Zheng xiao. Ji hai-chun. Acupoint embedding therapy for 40 cases of simple obesity [J].Journal of External Therapy of Traditional Chinese Medicine,201524(6):28-29. DOI:10.3969/ j.issn.1006-978x. 2015.06.016.[Chinese].

37. Zheng X. Ji Hai-chun, Nie Ling-juan, et al. Effect observation of PGLA acupoint embedding therapy for simple obesity [J].Shanghai Journal of Acupuncture and Moxibustion. DOI:10.13460/ J.issn.10050957.2018.04.0391.[Chinese].

38. Zhou Li L, Jie M, Wen, et al. Clinical study on painless acupoint embedding therapy for simple obesity [J]. World Journal of Traditional Chinese Medicine,2017,12(7):1645-1647,1651. DOI:10.3969/j.issn.1673-7202.2017.07.042.[Chinese].

39. Wei Z, Feng ZZhong-yu,Hu, San-chun T, Le Yu. Wang Jia-jie, Yu Pei-hao, Zheng Yi-wei, Liu Yan-ran. Clinical comparison of electroacupuncture and acupoint catgut embedding therapy in the treatment for simple obesity [J]. Liaoning Journal of Traditional Chinese Medicine,2020,47(09):156-159. [Chinese].

40. Zhu qi. Treatment of simple obesity by embedding absorbable wires into acupoints in 33 patients [J]. Zhejiang Journal of Traditional Chinese Medicine,2017,52(11):841.[Chinese].

\section{Figures}




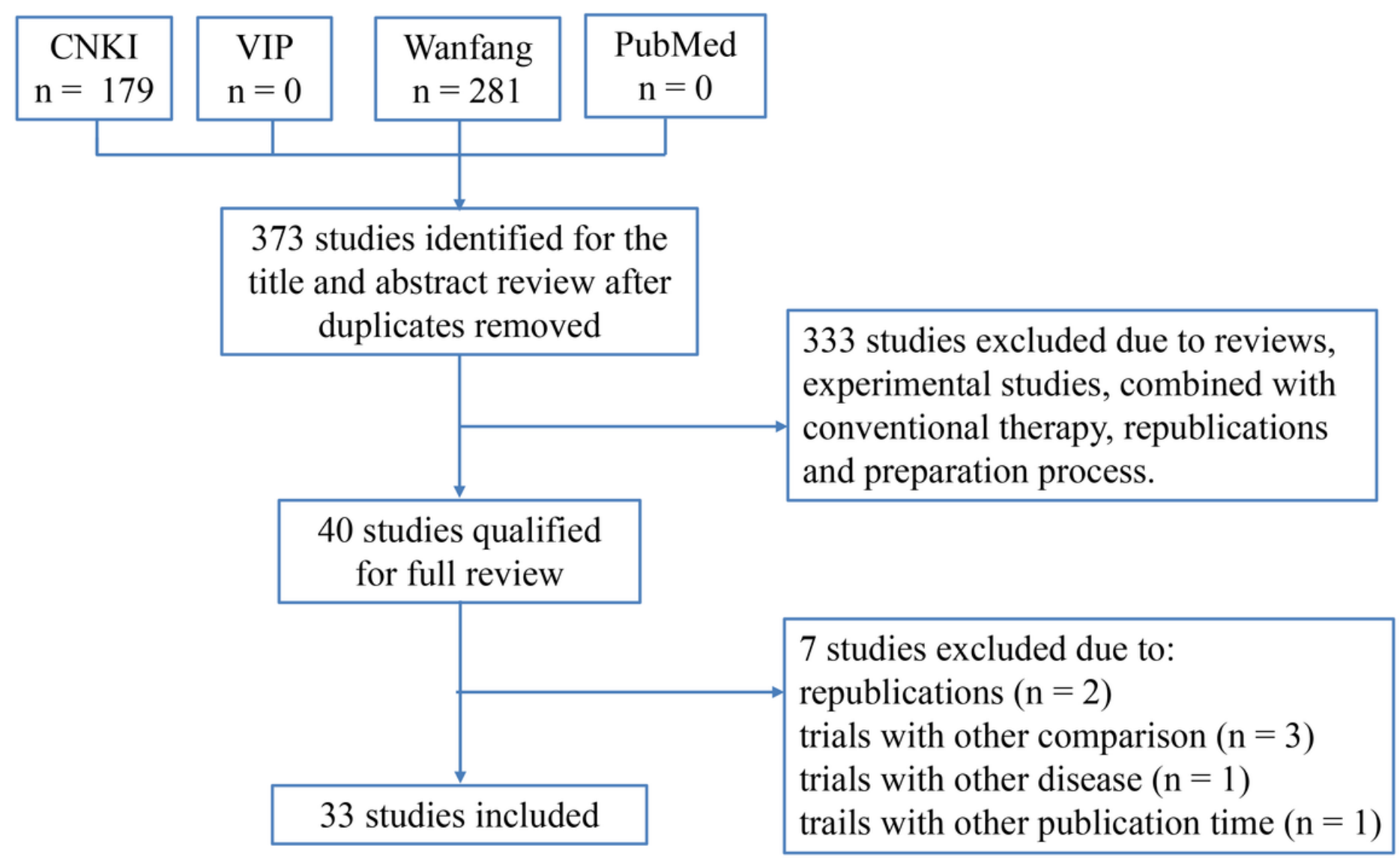

Figure 1

Flowchart of study searches and screening.

Random sequence generation (selection bias)

Allocation concealment (selection bias)

Blinding of participants and personnel (performance bias)

Blinding of outcome assessment (detection bias)

Incomplete outcome data (attrition bias)

Selective reporting (reporting bias)

Other bias
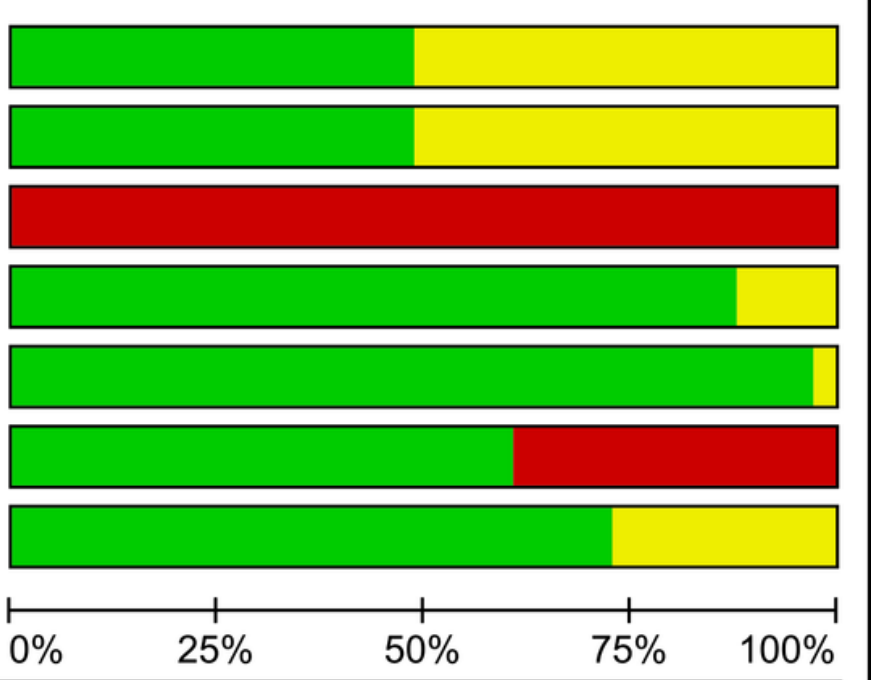
Figure 2

Risk of bias evaluation of included studies.

\begin{tabular}{|c|c|c|c|c|c|c|c|c|c|}
\hline \multirow{2}{*}{ Study or Subgroup } & \multicolumn{2}{|c|}{ Experimental } & \multirow{2}{*}{\multicolumn{2}{|c|}{$\begin{array}{l}\text { Control } \\
\text { Events }\end{array}$}} & \multirow{2}{*}{ woight } & \multirow{2}{*}{$\begin{array}{l}\text { Risk Ratio } \\
\text { M.t. Fixed. } 95 \% \mathrm{Cl}\end{array}$} & \multirow{2}{*}{\multicolumn{3}{|c|}{$\begin{array}{l}\text { Risk Ratio } \\
\text { M.H. Fixed. } 95 \% \mathrm{Cl}\end{array}$}} \\
\hline & Events & Total & & & & & & & \\
\hline Chen J2020 & 28 & 30 & 26 & 30 & $3.4 \%$ & & & 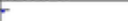 & \\
\hline Chen RZ2016 & 45 & 47 & 39 & 47 & $5.1 \%$ & $1.15[1.00,1.33]$ & & - & \\
\hline Chen YY2015 & 31 & 40 & 33 & 40 & $4.3 \%$ & $0.94[0.75,1.17]$ & & & \\
\hline Di YL2016 & 38 & 41 & 39 & 41 & $5.1 \%$ & $0.97[0.87,1.09]$ & & & \\
\hline He LY2017 & 28 & 30 & 23 & 28 & $3.1 \%$ & $1.14[0.93,1.38]$ & & - & \\
\hline Li MM2017 & 27 & 30 & 26 & 30 & $3.4 \%$ & $1.04[0.86,1.25]$ & & 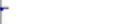 & \\
\hline Li MM2018 & 29 & 31 & 28 & 31 & $3.7 \%$ & $1.04[0.89,1.20]$ & & & \\
\hline LI QL2016 & 36 & 40 & 34 & 40 & $4.5 \%$ & $1.06[0.90,1.25]$ & & 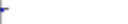 & \\
\hline Liu Y2019 & 28 & 31 & 29 & 31 & $3.8 \%$ & $0.97[0.83,1.12]$ & & & \\
\hline Qi L2016 & 28 & 30 & 22 & 30 & $2.9 \%$ & $1.27[1.01,1.61]$ & & {[} & \\
\hline Ren CC2016 & 33 & 36 & 32 & 36 & $4.2 \%$ & $1.03[0.89,1.20]$ & & & \\
\hline Sun FJ2020 & 25 & 25 & 21 & 25 & $2.8 \%$ & $1.19[0.99,1.43]$ & & $\sigma$ & \\
\hline Wang Z2020 & 54 & 56 & 44 & 56 & $5.8 \%$ & $1.23[1.06,1.42]$ & & & \\
\hline Wu XM2015 & 29 & 32 & 24 & 30 & $3.2 \%$ & $1.13[0.92,1.40]$ & & [ & \\
\hline Wu XN2017 & 66 & 76 & 59 & 73 & $7.9 \%$ & $1.07[0.93,1.24]$ & & 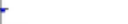 & \\
\hline Xu DJ2019 & 23 & 30 & 17 & 30 & $2.2 \%$ & $1.35[0.93,1.96]$ & & {[} & \\
\hline Yang Q2015 & 29 & 30 & 26 & 30 & $3.4 \%$ & $1.12[0.95,1.30]$ & & - & \\
\hline Yang YF2015 & 59 & 65 & 52 & 65 & $6.8 \%$ & $1.13[0.98,1.31]$ & & & \\
\hline Zhang H2017 & 39 & 40 & 32 & 40 & $4.2 \%$ & $1.22[1.04,1.43]$ & & - & \\
\hline Zhang HT2015 & 26 & 30 & 22 & 30 & $2.9 \%$ & $1.18[0.91,1.53]$ & & & \\
\hline Zhang Y2017 & 30 & 33 & 24 & 33 & $3.1 \%$ & $1.25[0.99,1.58]$ & & - & \\
\hline Zheng $\times 2015$ & 36 & 40 & 33 & 40 & $4.3 \%$ & $1.09\{0.91,1.30\}$ & & 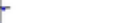 & \\
\hline Zheng X2018 & 40 & 43 & 38 & 43 & $5.0 \%$ & $1.05[0.92,1.21]$ & & & \\
\hline Zhou LJ2017 & 20 & 33 & 10 & 33 & $1.3 \%$ & $2.00[1,11,3.59]$ & & & \\
\hline Zhu 02017 & 28 & 33 & 27 & 33 & $3.5 \%$ & $1.04[0.84,1.29]$ & & - & \\
\hline Total $(95 \% \mathrm{Cl})$ & & 952 & & 945 & $100.0 \%$ & $1.12[1.08,1.16]$ & & 1 & \\
\hline & & & \\
\hline & & & & & & & $0.01 \quad 0.1$ & & ${ }_{100}$ \\
\hline \multicolumn{7}{|c|}{$\begin{array}{l}\text { Heterogeneity: } \mathrm{Ch}^{2}=27.21, \text { of }=24(P=0.29) ; P^{2}=12 \% \\
\text { Test for overall effect: } Z=5.83(P<0.00001)\end{array}$} & Favours [experime & Favours [control] & \\
\hline
\end{tabular}

\begin{tabular}{|c|c|c|c|c|c|c|c|c|c|c|c|}
\hline \multicolumn{12}{|c|}{ (a) Effectiveness Rate } \\
\hline & & \multicolumn{3}{|c|}{ Acupuncture } & \multirow{2}{*}{\multicolumn{2}{|c|}{$\begin{array}{ll} & \text { Mean Difference } \\
\text { Weight } & \text { IV.Random.95\% Cl }\end{array}$}} & \multirow{2}{*}{\multicolumn{3}{|c|}{$\begin{array}{l}\text { Mean Difference } \\
\text { IV. Bandgm. } 95 \% \mathrm{CL}\end{array}$}} \\
\hline 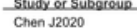 & 25.49 & 301 & & 264 & 303 & & & & & & \\
\hline Di YL2016 & 27.11 & 302 & 41 & 2705 & 3.11 & 41 & $5.8 \%$ & $0.06|127,1,39|$ & & & \\
\hline He LY2017 & 24.43 & 2.96 & 30 & 26.83 & 3.03 & 28 & $5.5 \%$ & $-240[-394-0.06]$ & & & \\
\hline Huang O22020 & 25.41 & 1.18 & 39 & 27.67 & 2.65 & 39 & $6.2 \%$ & $-226(-3.17,-1.35)$ & & & \\
\hline Li MM2017 & 28.157 & 4.1553 & 30 & 27.627 & 2.4666 & 30 & $5.3 \%$ & $0.53[-120.2 .26]$ & & & \\
\hline LiMM2018 & 29.18 & 4.43 & 33 & 27.91 & 2.67 & 33 & $5.3 \%$ & $1.27[-0.49 .3 .03\}$ & & & \\
\hline Liu Y2019 & 32.09 & 4.85 & 31 & 30.68 & 4.57 & 31 & $4.6 \%$ & $1.41[-0.94,3.76]$ & & & \\
\hline Ren CC2016 & 27.19 & 3.53 & 36 & 27.54 & 3.81 & 36 & $5.4 \%$ & $.0 .35[-2.05,1.35]$ & & & \\
\hline Wang Z2020 & 22.13 & 2.39 & 56 & 30.34 & 4.08 & 56 & $5.9 \%$ & $-8.21[-9.45,-6.97]$ & - & & \\
\hline Wu XM2015 & 26.1 & 2.9 & 32 & 27.6 & 2.7 & 30 & $5.7 \%$ & $-1.50[-2.89,-0.11]$ & & & \\
\hline Wu XN2017 & 26.58 & 5.93 & 76 & 27.1 & 6.42 & 73 & $5.0 \%$ & $-0.52[-2.51,1.47]$ & & & \\
\hline Xu DN2019 & 27.08 & 265 & 30 & 28.21 & 1.72 & 30 & $6.0 \%$ & $-1.13\{-2.26,0.00\}$ & & & \\
\hline Zhang $\mathrm{H}_{2} 017$ & 26.12 & 8.07 & 40 & 26.81 & 8.66 & 40 & $3.2 \%$ & $-0.69[-4,36,2.98]$ & & & \\
\hline Zhang Y2017 & 23.55 & 236 & 33 & 24.28 & 3.28 & 33 & $5.7 \%$ & $-0.73[-2.11,0.65]$ & & & \\
\hline Zheng X2015 & $\begin{array}{l}24.38 \\
23.22\end{array}$ & 228 & 40 & 26.01 & 2.04 & 40 & $6.1 \%$ & $\begin{array}{l}-1.63[-2.58,-0.68] \\
\end{array}$ & & & \\
\hline $\begin{array}{l}\text { Zheng X2018 } \\
\text { Zhow LJ2017 }\end{array}$ & $\begin{array}{r}2322 \\
28091\end{array}$ & $\begin{array}{r}1.89 \\
1.749\end{array}$ & & $\begin{array}{r}24.09 \\
29.898\end{array}$ & $\begin{array}{r}1.98 \\
1.152\end{array}$ & ${ }_{33}^{43}$ & $\begin{array}{l}6.2 \% \\
6.3 \%\end{array}$ & $\begin{array}{l}-0.87-1.69,-0.055 \\
0.09-0.250 .081\end{array}$ & & & \\
\hline Zhu 02017 & $\begin{array}{r}28.9811 \\
25.67\end{array}$ & $\begin{array}{r}1.749 \\
2\end{array}$ & ${ }_{33}^{33}$ & $\begin{aligned} 28.688 \\
26.63\end{aligned}$ & $\begin{array}{r}1.152 \\
1.69\end{array}$ & ${ }_{33}^{33}$ & $\begin{array}{l}6.3 \% \\
6.2 \%\end{array}$ & $\begin{array}{l}-0.099[-0.62,2.887]] \\
-0.96[-1.85,-0.07]\end{array}$ & & & \\
\hline \multirow{2}{*}{\multicolumn{9}{|c|}{ 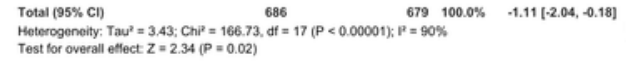 }} & & & \\
\hline & & & & & & & & & $\begin{array}{lll}-100 & 1 & + \\
-50 & + \\
\end{array}$ & $\begin{array}{c}1 \\
50 \\
\text { Fayours }\end{array}$ & ${ }_{100}$ \\
\hline
\end{tabular}

\begin{tabular}{|c|c|c|c|c|c|c|c|c|c|}
\hline \multicolumn{10}{|c|}{ (b) BMI } \\
\hline Study or Subgroup & \multicolumn{2}{|c|}{ ACE } & \multicolumn{3}{|c|}{$\begin{array}{c}\text { Acupuncture } \\
\text { SD Total }\end{array}$} & \multicolumn{2}{|c|}{$\begin{array}{l}\text { Mean Difference } \\
\text { Weight IV.Random. } 95 \% \mathrm{CL}\end{array}$} & \multirow{2}{*}{\multicolumn{2}{|c|}{$\begin{array}{l}\text { Mean Difference } \\
\text { IV. Randem. } 95 \% \mathrm{Cl}\end{array}$}} \\
\hline Chen J2020 & 7345 & 1163 & 307778 & 1036 & 30 & $57 \%$ & $-433[9.90,124$ & & \\
\hline Chen R72016 & 856 & 84 & $47 \quad 914$ & 92 & 47 & $78 \%$ & 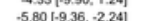 & - & \\
\hline He LY2017 & $\begin{array}{l}02.0 \\
82.39\end{array}$ & 932 & 3085.08 & 9.96 & 28 & $6.3 \%$ & -26917662281 & & \\
\hline L & 97.14 & 1265 & 33928 & 8.51 & $\begin{array}{l}20 \\
33\end{array}$ & 6.18 & $434[086,954 \mid$ & & \\
\hline tiu $Y 2019$ & 101.03 & 5.56 & 3196.55 & 5.72 & 31 & $87 \%$ & $448(167,729)$ & & \\
\hline Ren CC2016 & 87.86 & 538 & $36 \quad 89.36$ & 6.36 & 36 & $88 \%$ & $.150 \mid-422,122]$ & & \\
\hline Wu XM2015 & 92.17 & 347 & $32 \quad 94.46$ & 3.28 & 30 & $9.7 \%$ & $-229[-397,-0611$ & & \\
\hline Wu XN2017 & 902 & 13.95 & $\begin{array}{lll}76 & 91.66\end{array}$ & 14.68 & 73 & $67 \%$ & $.146[606,3.14]$ & & \\
\hline Xu D.J2019 & 84.89 & 35 & 3091.65 & 1.96 & 30 & $9.9 \%$ & $-6.76[-820.532]$ & . & \\
\hline Zhang $\mathrm{H} 2017$ & 82.51 & 8.18 & $40 \quad 86.74$ & 2.21 & 40 & $8.9 \%$ & $-4.23[-6.86,-1.60)$ & & \\
\hline Zhang Y2017 & 85.33 & 4.04 & $33 \quad 88.59$ & 6.26 & 33 & $8.9 \%$ & $-3.26|-5.80,-0.72|$ & & \\
\hline Zheng X2015 & 80.02 & 16.37 & $\begin{array}{lll}40 & 83.74\end{array}$ & $\begin{array}{r}0.26 \\
15.43\end{array}$ & 40 & $\begin{array}{l}4.6 \% \\
4.6 \%\end{array}$ & $-3.72|-10.69,3.25|$ & & \\
\hline Zheng X2018 & 84.07 & 8.09 & $\begin{array}{lll}43 & 85.23\end{array}$ & 8.79 & 43 & $7.8 \%$ & $-1.16[-4.73,2.41]$ & & \\
\hline \multirow{2}{*}{\multicolumn{8}{|c|}{ 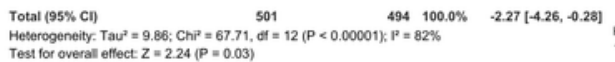 }} & + & \\
\hline & & & & & & & & 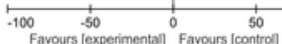 & ${ }_{100}$ \\
\hline
\end{tabular}

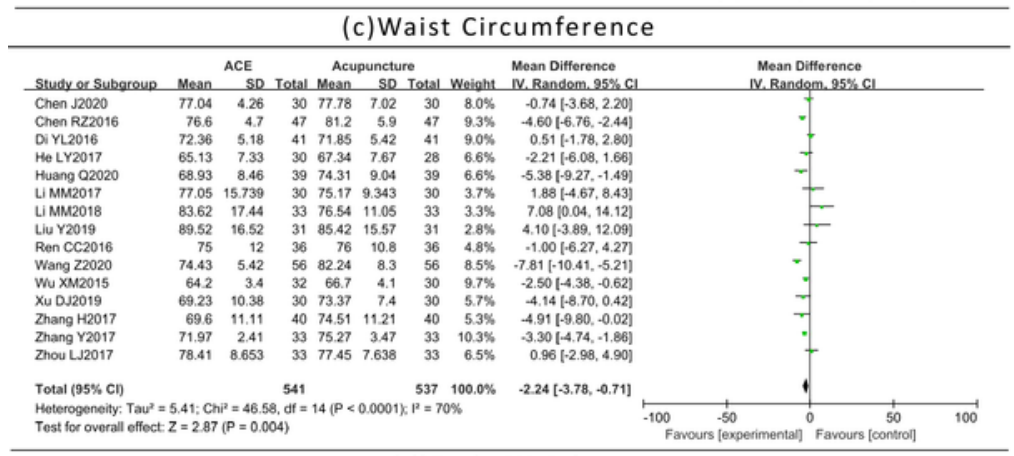

(d) Body Weight

\section{Figure 3}

Comparison between ACE and Acupuncture. 


\begin{tabular}{|c|c|c|c|c|c|c|c|c|c|c|c|}
\hline \multirow[b]{2}{*}{ Study or Subgroup } & \multicolumn{2}{|c|}{ Experimental } & \multicolumn{2}{|c|}{ Control } & \multirow[b]{2}{*}{ Weight } & \multirow{2}{*}{$\begin{array}{c}\text { Odds Ratio } \\
\text { M-H. Fixed. } 95 \% \mathrm{Cl}\end{array}$} & \multirow{2}{*}{\multicolumn{5}{|c|}{$\begin{array}{c}\text { Odds Ratio } \\
\text { M-H. Fixed. } 95 \% \mathrm{Cl}\end{array}$}} \\
\hline & Events & Total & Events & Total & & & & & & & \\
\hline Duan YQ2018 & 24 & 25 & 20 & 25 & $2.7 \%$ & $6.00[0.65,55.66]$ & & & & & \\
\hline Huang W2017 & 35 & 40 & 34 & 40 & $14.3 \%$ & $1.24[0.34,4.43]$ & & & & & \\
\hline Jin WW2016 & 74 & 80 & 58 & 80 & $14.6 \%$ & $4.68[1.78,12.29]$ & & & & & \\
\hline Wu XN2015 & 66 & 76 & 59 & 73 & $26.6 \%$ & $1.57[0.65,3.79]$ & & & & & \\
\hline Xu WZ2017 & 29 & 30 & 23 & 30 & $2.6 \%$ & $8.83[1.01,76.96]$ & & & & & \\
\hline Yan XR2015 & 24 & 26 & 25 & 27 & $6.3 \%$ & $0.96[0.13,7.37]$ & & & & & \\
\hline Zhao HY2015 & 28 & 36 & 22 & 29 & $18.2 \%$ & $1.11[0.35,3.55]$ & & & & & \\
\hline Zhou W2019 & 40 & 45 & 39 & 45 & $14.6 \%$ & $1.23[0.35,4.37]$ & & & & & \\
\hline Total $(95 \% \mathrm{Cl})$ & & 358 & & 349 & $100.0 \%$ & $2.11[1.38,3.24]$ & & & & & \\
\hline Total events & 320 & & 280 & & & & & & & & \\
\hline \multicolumn{7}{|c|}{ Heterogeneity: $\mathrm{Chi}^{2}=8.69, \mathrm{df}=7(\mathrm{P}=0.28) ; \mathrm{I}^{2}=19 \%$} & 0.0 & 0.1 & 1 & 10 & 100 \\
\hline \multicolumn{7}{|c|}{ Test for overall effect: $Z=3.42(P=0.0006)$} & $\begin{aligned} 0.01 \\
\mathrm{Fa}\end{aligned}$ & 0.1 & nental] & Favours [control] & 100 \\
\hline
\end{tabular}

\section{(a) Effectiveness Rate}

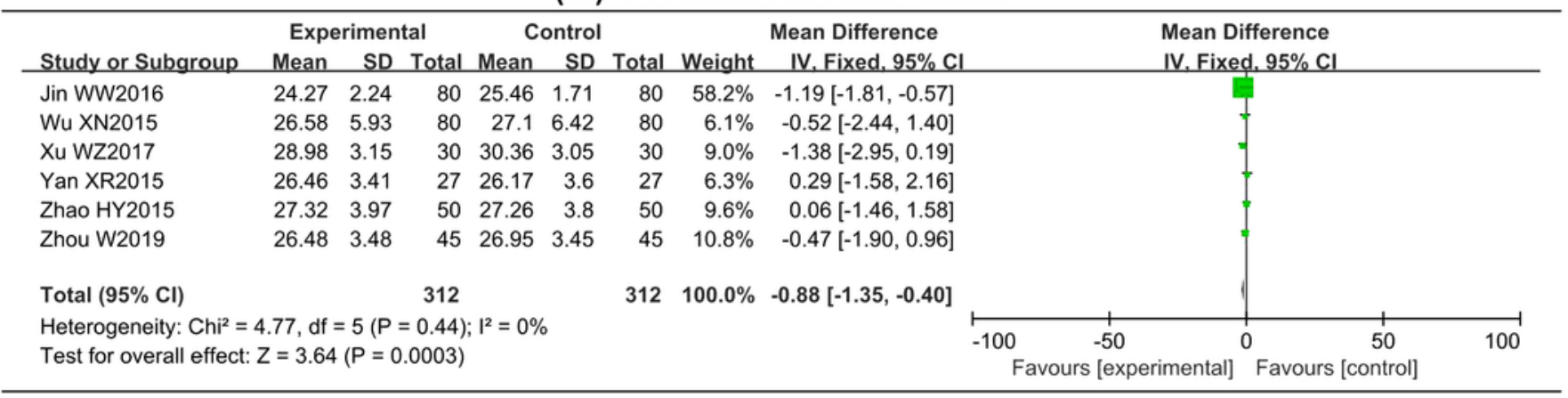

(b) BMI

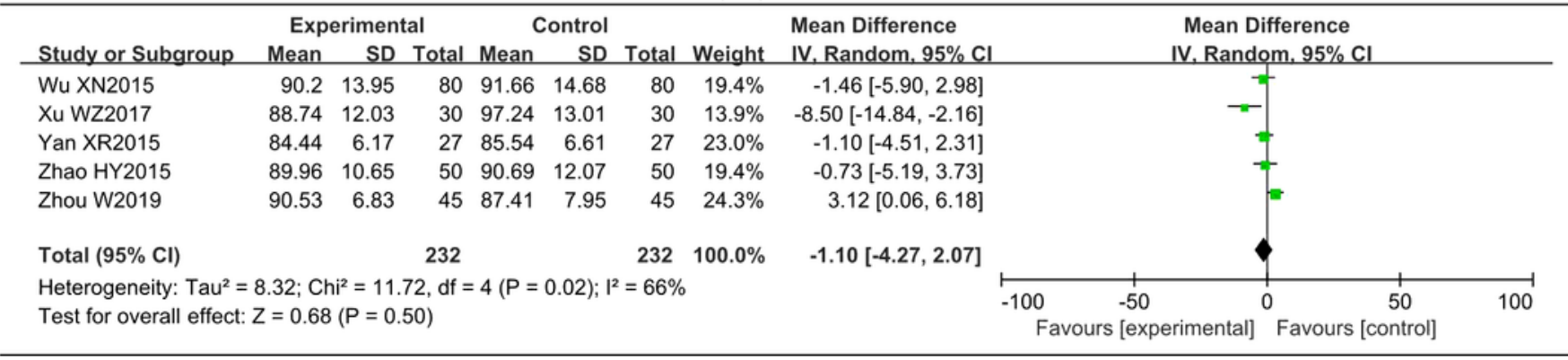

\section{(c) Waist Circumference}

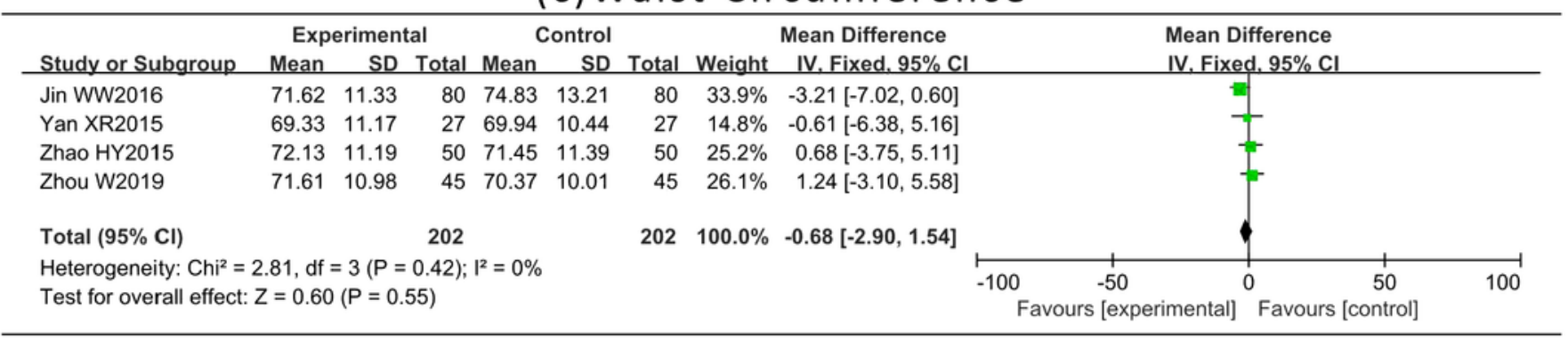

(d) Body Weight

Figure 4

Comparison between ACE and Acupuncture(plus diet and exercise).

\section{Supplementary Files}

This is a list of supplementary files associated with this preprint. Click to download. 
- PRISMA2009checklist.doc

Page 19/19 